\title{
Determinants of Saving Behavior Among Private Sector Employees in Malaysia: An Empirical Investigation
}

\author{
Shafinar Ismail ${ }^{1}$, Azreenabila Norliza ${ }^{2}$, Mohd Halim Mahphoth ${ }^{3}$, Rohaiza Kamis ${ }^{4}$, Mohd \\ Isham Abidin $^{5}$, Sumayyah Shaidin ${ }^{6}$, Suzila Ismail ${ }^{7}$ \\ \{shafinar138@gmail.com ${ }^{1}$ \} \\ Universiti Teknologi MARA, Malaysia ${ }^{1,2,3,4,5,6}$ \\ Universiti Utara Malaysia, Malaysia ${ }^{7}$
}

\begin{abstract}
Malaysian's savings rate has declined in recent years. The last generation was more disciplined about savings. However, it seems that nowadays, Malaysians, in general, tend to save less. The growth of individual savings has been declined since 2017. According to a survey conducted in Malaysia in 2019, 35 percent of respondents saved less than 500 Malaysian Ringgit monthly. In 2018, the highest group of respondents who saves money frequently was people between the age of 15 to 24 years, with around 73 percent. Therefore, the purpose of this research was to investigate the determinants of saving behaviour of private-sector employees in Malaysia. Questionnaires were distributed to the 150 employees at a local financial institution. The sampling procedure adopted in this research was purposive sampling. Mean and standard deviation were computed for descriptive analysis as well as reliability analysis were also tested to examine the internal consistency of the items in the respective factors. Multiple regression analysis was used primarily to test the hypothesis proposed. The results of this study posited that financial knowledge and retirement planning have a strong influence on saving behaviour, while financial planning was found to be the least important factor in saving behaviour.
\end{abstract}

Keywords: Saving Behaviour, Financial Knowledge, Retirement Planning, Financial Planning

\section{Introduction}

Personal debt issues are not globally unusual. Excessive debts have brought default payments and ended up with the declaration of personal bankruptcy. Although personal bankruptcy files in Malaysia have gathered to 124,708 cases from 2005 to 2012 (AKPK 2015), the increase number of individual insolvency cases was because of the decline in the credit assessment process. Previously, bankruptcy filings are because of a heightened number of individual debts to their level of income [1], and this calculation is regularly utilized as a measurement by numerous analysts. Zywicki [2] stated that the debt-to-income ratio looks unbalanced because of mortgages and loan instalments allude to long haul obligation, however the proportion of pay will be the transient pay. Meanwhile, Brown and Taylor [3] contended that a few families with high debt levels are responsible with negative total assets and end up with short-term bankruptcy filing. 
Unfortunately, young adults who are presently in their university life have inadequate abilities in dealing with their own financing. This is a general public's concern as it could be a factor of the disparity in the distribution of income and wealth, insufficient resources for retirement, low investment and capital aggregation because of the limited financial knowledge and skills [4]. A report of spending trends of employees in Malaysia, sourced by Malaysia's official statistics indicated that most Malaysians spent on residential water, energy gas and other fuels.

Malaysia's saving rate has declined as of late. According to data from the World Bank, Malaysia's Gross Domestic Savings (percentage of GDP) ranged from 42\% to $43 \%$ from 1999 to 2008 but fell abruptly to $36 \%$ in 2009. An "Asian Survey Monitor" done by HSBC Bank in 2010 also discovered a lower personal savings rate among Malaysians as they found that average Malaysians spared only 25 per cent of their income and 79 per cent were for excessive expenses rather than other purposes, e.g., health care, retirement or investment. Furthermore, $60 \%$ of respondents revealed that they did not save adequately and 15 per cent of respondents did not save at all. Studies have indicated that inadequate savings are commonly due to their spending forecast [5], insufficient self-control [6], harping on the present instead of things to come [7], or the consequences of culture [8]. In a survey conducted in Malaysia in 2019, around 35 percent of respondents saved below 500 Malaysian Ringgit per month. In 2018, the highest number of respondents saving money was among individuals aged between 15 and 24 years, with around 73 percent.

Saving if usually observed as a significant commitment to promote long-term economic development. It is also a major aspect in establishing an economic link between a nation's past, current and future. The amount of savings accessible in a nation restricts the level of its gross investment and its rate of development. Lower savings would result in huge investments opportunities that can improve economic growth. To boost saving, government policies should concentrate on giving more incentives and saving opportunities by offering wide-ranging investments. When families save too little, emotionally and without emergency savings, this will lead to anxiety and serious health problems [9].

Therefore, the objective of this paper is to examine the determinants of saving behaviour among employees in Malaysia. Understanding the determinants of saving behaviour among employees at the current situation will assist various parties such as heads of departments in the organization, top-level management, employees as well their families, friends as well colleagues for a better administration their calculation now and future to minimize mistakes in handling money. The rest of the paper is structured as follows. In the next section, we highlight related empirical studies and theoretical frameworks suitable for this subject. Section 3 outlines the research methodology used in this study. Section 4 presents the results of the data analysis collected through multiple regression analysis. Lastly, section 5 concludes by giving a review of all the data analysis mentioned in the previous section, hence validating the significant findings and implications of the study and provides the limitations of the study along with some suggestions or recommendations for further research.

\section{Literature Review}

Initiatives on financial education have been recognized as essentials in improving financial knowledge and nurturing personal financial responsibility for individuals without financial experience [10]. While current literature has shown a positive link between improved financial knowledge and successful saving behaviors, studies have also shown that students do not have 
enough financial knowledge and training in management [11]. On the other hand, in a comparative study conducted by Koposko et al. [12] on the United States and Mexican undergraduates, they possessed only marginally assured of financial knowledge and financial education during their study periods. The study also noted despite that; the participants were conscious or worried about the value of actively preparing their future financial and most important, pension or retirement. Kotlikoff and Bernheim [13] stated that increased awareness led to increased savings. Shim et al. [14] added by stating that having financial knowledge is crucial to foresee financial behaviors that eventually lead to excellent financial behaviour. They confirmed through a study that financial knowledge is directly linked to financial behaviour. Sang et al. [15] mentioned that the level of financial knowledge has no direct impact on financial decisions, but to result in a positive attitude to financial conduct. The discussion proved to be critical in this regard in financial terms. It is also necessary to address the possible implications of subjective financial knowledge (or self-assessed knowledge). Courchane [16] noted that one of the critical factors in determining financial attitudes is self-assessed knowledge. Nevertheless, the results of the study showed that people do not always need to have a full financial understanding [16]. Therefore, the following hypothesis is established:

\section{H1: Financial knowledge has a significant relationship towards saving behaviour}

Governments all over the world have started to promote a new, more responsible approach to individual finance over the last decade to enable people to be more accountable for their financial well-being. The 2008 global financial crisis and the subsequent recession have severely affected households, pushing public policies away from the most commonly used economic support to improve consumer investment and raise consumer awareness of individuals long-term financial needs and resources. The shift in policy intensifies the value of households' capability to be financially responsible and saving for their future needs. With the present-day situation whereby more personal savings are required, it is vital to realize why some are making suitable investments while others are struggling. According to Campbell [17], not many are well informed and able to make well educated economic decisions. Lusardi and Mitchell [4] mentioned that based on their study, $45 \%$ of baby boomers aged 51-56 years have little or no financial planning thus hitting their golden years in low wealth and depending only on the pension savings as the Employment Provident Fund. (EPF). Therefore, the following hypothesis is developed:

\section{H2: Financial planning has a significant relationship towards saving behaviour}

Retirement planning is a strategy a person makes so that they can be prepared for life after paid work, not only in terms of finances but in all aspects of life. One example is preparing how to live and prosper in retirement for the rest of their lives. In Malaysia, most of the employees will be retired in the age between 55 or 60 . After their retirement, they will lose their monthly source of income and continue their living using their savings money. Mitchell [18] has highlighted that planning is the primary indicator for saving enough for retirement. In this case, people will start to save money for retirement to get through the retirement phase. During the retirement period, households also need to spend money similarly as when they were still working time. Previous research has shown that older people tend to have a significantly positive attitude towards money than the younger generation [19]. Thus, to avoid suffering in retirement planning troughs, people need to budget financially. The retirees need to be able to prevent 
having outstanding loans once they leave the workforce. Hence, the following hypothesis is developed:

\section{H3: Retirement planning has a significant relationship towards saving behaviour}

This study adopts the theory of planned behaviour (TPB) to explain the proposed framework. Based on the theory of planned behaviour, supposed behavioral control can be used to forecast actions directly. This inference may be supported by the influences of perceived regulation of behavioral performance, which some people regard as a control locus that can account for a large variance in actions. For example, past study shows that by linking the financial resource model with the planned behaviour theory, the overall view of the relationship between saving behaviour, financial planning, financial knowledge, and control location will be revealed [20]. Moreover, the theory of planned behaviour describes the connection between beliefs, desire, and behaviour [21]. Based on the discussion in the previous section, the following theoretical model has been developed (Figure 1).

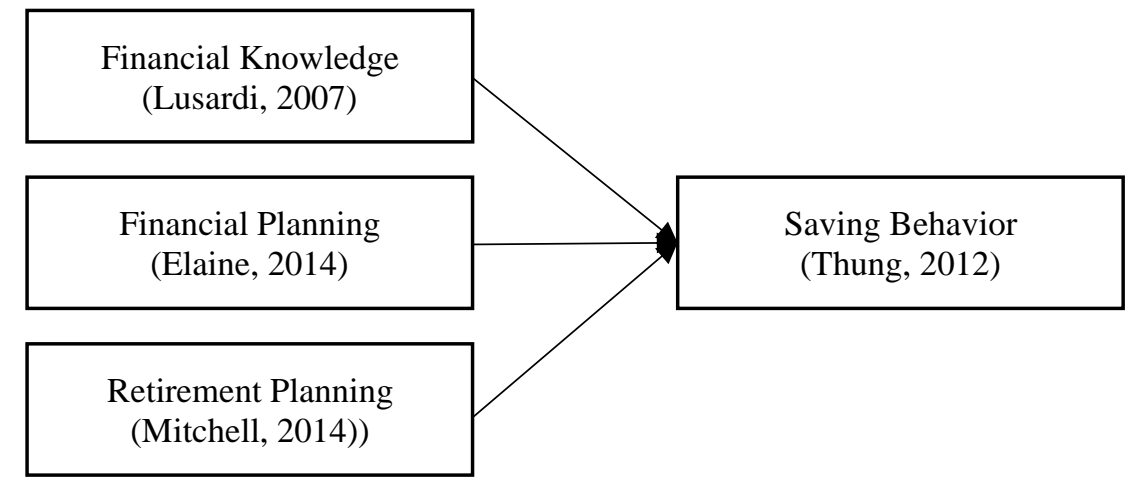

Fig. 1. Proposed theoretical framework

\section{Methodology}

The respondents in this study are employees currently working in XXX companies. In regards to the sampling technique, a non-probability sampling known as purposive sampling is used in this study. This study uses questionnaire as its data-gathering instrument in which the question items are adapted from several previous studies and consists of five sections namely: section (A) "demographics profile", section (B) "saving behaviour", section (C), "financial knowledge" section (D) "financial planning" and section (E) "retirement planning". In the questionnaire, saving behaviour will be measured using ten items adapted from Washington et al. [22]; financial knowledge will be measured using ten items adapted from Bongomin et al. [23]; financial planning will be measured using 11 items adapted from Rehman et al. [24]; and retirement planning will be measured using ten items adapted from Ridgway [25]. The items are measured using a 5-point Likert scale ranging from (1) strongly disagree to (5) strongly agree. Frequency analysis will be employed to extract percentage-based data from the profiles of respondents regarding age, gender, race, income level, educational background, marital status and amount of dependency. Mean, and standard deviation will then be computed for descriptive 
analysis. Next, the reliability test will be used to examine the internal consistency of the items in their respective factors, and multiple regression analysis will be used primarily to test the hypotheses proposed earlier.

\section{Results}

Table 1. Respondents' Profile

\begin{tabular}{|c|c|c|c|}
\hline Demographic Factor & Categories & Frequency & Percentage \\
\hline \multirow[t]{3}{*}{ Age } & $21-30$ & 85 & 56.0 \\
\hline & $31-40$ & 57 & 38.0 \\
\hline & $41-50$ & 9 & 6.0 \\
\hline \multirow[t]{2}{*}{ Gender } & Female & 104 & 69.3 \\
\hline & Male & 46 & 30.7 \\
\hline \multirow[t]{4}{*}{ Race } & Malay & 117 & 78.0 \\
\hline & Chinese & 19 & 12.7 \\
\hline & India & 12 & 8.0 \\
\hline & Others & 2 & 1.3 \\
\hline \multirow[t]{4}{*}{ Income Level } & $<$ RM 1000 & 7 & 4.7 \\
\hline & RM 1000 - RM 2000 & 19 & 12.7 \\
\hline & RM 2001 - RM 3000 & 68 & 45.3 \\
\hline & RM 3001 - RM 4000 & 26 & 17.3 \\
\hline \multirow[t]{7}{*}{ Education Background } & SPM & 7 & 4.7 \\
\hline & Certificate & 10 & 6.7 \\
\hline & Diploma & 58 & 38.7 \\
\hline & Degree & 53 & 35.3 \\
\hline & Master & 13 & 8.7 \\
\hline & $\mathrm{PhD}$ & 6 & 4.0 \\
\hline & Others & 3 & 2.0 \\
\hline \multirow[t]{3}{*}{ Marital Status } & Single & 62 & 41.3 \\
\hline & Married & 81 & 54.0 \\
\hline & Divorce & 7 & 4.7 \\
\hline \multirow[t]{4}{*}{ No. of Dependency } & 0 & 55 & 36.7 \\
\hline & $1-2$ & 60 & 40.0 \\
\hline & $3-4$ & 25 & 16.7 \\
\hline & More than 4 & 10 & 6.7 \\
\hline
\end{tabular}

As presented in Table 1, a total of 150 respondents participated in this study, resulted in $100 \%$ return rates. Out of 150 respondents, $56 \%$ of respondents aged between $21-30,38 \%$ of respondents were between 31-40, while only $6 \%$ of respondents were between 41-50. Moreover, $69.3 \%$ of the respondents were female, while only $30.7 \%$ of the respondents were male. Most of the respondents were Malay (78\%), followed by Chinese $(12.7 \%)$, India $(8 \%)$ and others $(1.3 \%)$. Most of the respondents have monthly income level ranges between RM2000-RM3000 (45.3\%) followed by $17.3 \%$ of respondents have monthly income level ranging between RM 3001-RM4000 followed by $12.7 \%$ of the respondents have monthly income level ranging RM1000-RM2000 and the least number of respondents (4.7\%) earned less than RM1000 (4.7\%). As for their educational background, $38.7 \%$ of the respondents, which is the highest percentage possessed diplomas, followed by degree $(35.3 \%)$. Other qualifications were SPM 
(secondary school level) (4.7\%), postgraduates such as masters $(8.7 \%)$ and $\mathrm{PhD}(4 \%)$ and other non-specified qualifications $(2 \%)$. Out of 150 respondents, $54 \%$ were married, followed by unmarried (41.3\%) and divorced (4.7\%). Next, for dependency, the highest percentage of participants with one or two dependencies was $40 \%$, followed by respondents with no dependency $(36.7 \%)$, three to four dependencies $(16.7 \%)$ and the least percentage of respondents with more than four dependencies was $6.7 \%$.

\subsection{Descriptive Analysis}

Next, the results of the descriptive analysis are presented. Comparing price behaviour obtained the highest mean score (3.84), which indicated that it is the most influential item of saving behaviour among the participants. However, saving at the end of the month received the lowest mean score (3.60), which showed that most participants did not favor the item as a preferable saving behaviour. On the next variable, which is financial knowledge, participants' knowing on personal budget received the highest mean score (3.69) while getting acquainted with current financial news obtained the lowest mean score (3.48). This shows that these participants were aware of the importance of planning for a personal budget. As for the third variable; Monthly Financial Planning, financial planning attained the highest mean score (3.74). This indicated that they were doing their financial planning monthly, but they did not focus on recording their expenses as it received the lowest mean score (3.59). Finally, under the retirement planning variable, having a clear vision on retirement received the highest mean score (3.68) which showed that the respondents acknowledged they already have a clear view of how their life will be in after their retirement. Nevertheless, failure in preparation obtained the lowest mean (3.52). This showed that the respondents agreed that they were insufficiently prepared for retirement due to various of commitment.

Table 2. Regression Result

\begin{tabular}{llllll}
\hline \multicolumn{2}{c}{ Hypotheses } & Beta & t-value & p-value & Supported \\
\hline $\mathrm{H}_{1}$ & $\begin{array}{l}\text { Saving Behavior } \\
\text { Financial knowledge has a significant } \\
\text { relationship with saving behaviour }\end{array}$ & .776 & 8.347 & .000 & Yes \\
$\mathrm{H}_{2}$ & $\begin{array}{l}\text { Financial Planning has a significant } \\
\text { relationship saving behaviour }\end{array}$ & -.129 & 4.434 & .225 & No \\
$\mathrm{H}_{3}$ & $\begin{array}{l}\text { Retirement Planning has a significant } \\
\text { relationship saving behaviour }\end{array}$ & .171 & 7.123 & .030 & Yes \\
\hline
\end{tabular}

Table 2 demonstrated the study's regression results. The p-value should be less than 0.05 to describe the importance of the relationship. Financial knowledge obtains the highest value for beta (standardized coefficient) with 0.77 , and the p-value is 0.00 , which is less than 0.05 . Hence, $\mathrm{H} 1$ is supported. The second highest value for beta is retirement planning with 0.17 , and the p-value is 0.03 , which also less than 0.05 , which shows that H3 is supported. The lowest beta value in table 4 is retirement planning $(-0.12)$, and the p-value is 0.22 , which is more than 0.05 . Hence, $\mathrm{H} 2$ is not supported. 


\section{Conclusion}

This study aimed to investigate the factors affecting saving behaviour among privatesector employees. The results suggested that financial knowledge and retirement planning have a great influence on saving behaviour and it is consistent with the previous study conducted by Reay [26] which proved that saving have an essential role in improving economic growth over the past period. Furthermore, this study also shared the same results with Hilgert, Hogarth and Beverly [27] previous study on financial knowledge which revealed that there is a significant relationship between financial knowledge and saving behaviour. Mitchell [18] stated that planning is the primary indicator for saving enough for retirement. However, this study found that planning has no significance to be an indicator for retirement saving.

This study has several important implications for practitioners. Firstly, financial knowledge is an essential factor that should be considered by employees which can give an impact on saving behaviour. Employees can manage their finances well if they have the sufficient knowledge as well as being able to practice when making financial decisions. Ultimately, as far as government agencies are concerned, they need to organize more financial conferences, seminars and workshops to educate people on the importance of knowing financial management, including saving. However, financing planning is found insignificant in this study thus shows that in the context of this study, having no implementation on planning does not cause significant effects on saving. Next, retirement planning is found to be essential. To allow employees to feel satisfied with their financial condition, they must have a high level of confidence in managing their funds as it will help to protect their future.

The present study has some limitations. Since the study has been used the primary data, the sample size might be inaccurate, bias, as well as the data collected, may be unreliable and vague. This is because the sample size is too small to represent a large population. Future research requires a larger sample size to ensure an even representative distribution of a population in which the results can be generalized or transferred.

\section{References}

[1] E. Warren, "The bankruptcy crisis," Ind. LJ, vol. 73, p. 1079, 1997.

[2] T. J. Zywicki, "An economic analysis of the consumer bankruptcy crisis," Nw. UL Rev., vol. 99, p. 1463, 2004.

[3] S. Brown and K. Taylor, "Household debt and financial assets: evidence from Germany, Great Britain and the USA," J. R. Stat. Soc. Ser. A (Statistics Soc., vol. 171, no. 3, pp. 615-643, 2008.

[4] O. S. Mitchell, A. Lusardi, and V. Curto, "Financial literacy among the young: Evidence and implications for consumer policy," Pension Res. Counc. WP, vol. 9, 2009.

[5] G. Ülkümen, M. Thomas, and V. G. Morwitz, "Will I spend more in 12 months or a year? The effect of ease of estimation and confidence on budget estimates," J. Consum. Res., vol. 35, no. 2, pp. 245-256, 2008.

[6] R. F. Baumeister, K. D. Vohs, and D. M. Tice, "The strength model of self-control," Curr. Dir. Psychol. Sci., vol. 16, no. 6, pp. 351-355, 2007.

[7] J. G. Lynch Jr and G. Zauberman, "When do you want it? Time, decisions, and public policy," $J$. Public Policy Mark., vol. 25, no. 1, pp. 67-78, 2006.

[8] D. A. Briley and J. L. Aaker, "When does culture matter? Effects of personal knowledge on the correction of culture-based judgments," J. Mark. Res., vol. 43, no. 3, pp. 395-408, 2006.

[9] A. Prawitz, E. T. Garman, B. Sorhaindo, B. O’Neill, J. Kim, and P. Drentea, "InCharge financial distress/financial well-being scale: Development, administration, and score interpretation," $J$. Financ. Couns. Plan., vol. 17, no. 1, 2006. 
[10] T.-C. M. Peng, S. Bartholomae, J. J. Fox, and G. Cravener, "The impact of personal finance education delivered in high school and college courses," J. Fam. Econ. Issues, vol. 28, no. 2, pp. 265-284, 2007.

[11] S. Brobeck, "Student Consumer Knowledge: Results of a Nationwide Test.," 1991.

[12] J. L. Koposko, D. A. Hershey, M. I. Bojórquez, and A. E. Pérez, "College student attitudes toward retirement planning: the case of Mexico and the United States.," J. Pers. Financ., vol. 15, no. 2, 2016.

[13] L. J. Kotlikoff and B. D. Bernheim, "Household financial planning and financial literacy," Essays saving, bequests, altruism, life-cycle Plan., pp. 427-478, 2001.

[14] S. Shim, B. L. Barber, N. A. Card, J. J. Xiao, and J. Serido, "Financial socialization of first-year college students: The roles of parents, work, and education," J. Youth Adolesc., vol. 39, no. 12, pp. $1457-1470,2010$.

[15] L. T. Sang, "an Investigation of the Level and Determinants of Financial Literacy among Different Groups in Sabah." Universiti Malaysia Sabah, 2014.

[16] M. Courchane and P. Zorn, "Consumer literacy and creditworthiness," Proceedings, Fed. Reserv. Bank Chicago, 2005.

[17] J. Y. Campbell, "Household finance," J. Finance, vol. 61, no. 4, pp. 1553-1604, 2006.

[18] R. K. Mitchell et al., "The central question in entrepreneurial cognition research 2007," Entrep. theory Pract., vol. 31, no. 1, pp. 1-27, 2007.

[19] F. Tang and Y. Lee, "Social support networks and expectations for aging in place and moving," Res. Aging, vol. 33, no. 4, pp. 444-464, 2011.

[20] T. Yanai, Y. Kurashige, W. Mizukami, J. Chalupský, T. N. Lan, and M. Saitow, "Density matrix renormalization group for ab initio Calculations and associated dynamic correlation methods: A review of theory and applications," Int. J. Quantum Chem., vol. 115, no. 5, pp. 283-299, 2015.

[21] S. M. Danes and Y. Yang, "Assessment of the use of theories within the Journal of Financial Counseling and Planning and the contribution of the family financial socialization conceptual model," J. Financ. Couns. Plan., vol. 25, no. 1, 2014.

[22] C. I. Washington, R. Jamshidi, S. F. Thung, U. A. Nayeri, A. B. Caughey, and E. F. Werner, "Timing of postpartum intrauterine device placement: a cost-effectiveness analysis," Fertil. Steril., vol. 103, no. 1, pp. 131-137, 2015.

[23] G. Okello Candiya Bongomin, J. M. Ntayi, J. C. Munene, and I. N. Nabeta, "Financial inclusion in rural Uganda: Testing interaction effect of financial literacy and networks," J. African Bus., vol. 17, no. 1, pp. 106-128, 2016.

[24] A. Rehman, M. Farooq, A. Nawaz, and R. Ahmad, "Improving the performance of short-duration basmati rice in water-saving production systems by boron nutrition," Ann. Appl. Biol., vol. 168, no. 1 , pp. 19-28, 2016.

[25] D. A. Ridgway and M. A. Talib, "Globalization and Development-Free Trade, Foreign Aid, Investment and the Rule of Law," Cal. W. Int'l LJ, vol. 33, p. 325, 2002.

[26] D. Reay, "What would a socially just education system look like?: Saving the minnows from the pike," J. Educ. Policy, vol. 27, no. 5, pp. 587-599, 2012.

[27] J. M. Hogarth, S. G. Beverly, and M. Hilgert, "Patterns of financial behaviors: Implications for community educators and policy makers," 2003. 